\title{
La colonialidad en el presente global. A propósito del relato moderno sobre la diversidad cultural *
}

\author{
Valeria Belmonte**
}

\section{Resumen}

La visión liberal sobre la diversidad cultural impulsada desde varios organismos internacionales como la UNESCO y el PNUD merece ser revisada. En ella permanece incuestionada e invisibilizada la lógica de poder que interviene en la configuración de las diferencias que han sido históricamente establecidas entre grupos y poblaciones.

Para tal fin resulta apropiado acudir a los aportes teóricos, políticos, éticos y epistémicos que, desde mediados de los años 90, vienen siendo realizados por un grupo de intelectuales reunidos en torno a la perspectiva Modernidad-ColonialidadDecolonialidad (MCD).

Como estrategia metodológica para la indagación de la presencia de la matriz de poder colonial en el relato moderno sobre la diversidad, el artículo analiza las representaciones que se generan en torno a un colectivo de identificación de origen moderno como es la nación; en esta oportunidad se trata de representaciones de la Nación Argentina.

\footnotetext{
* Artículo recibido el 17 de Febrero de 2015. Aceptado el 25 de Julio de 2015.

** Docente e Investigadora de la Universidad Nacional del Comahue. Miembro del Centro de Estudios y Actualización en Pensamiento Político, Decolonialidad e Interculturalidad (CEAPEDI). Actualmente integra el proyecto de investigación Geopolítica del conocimiento y nuevas modalidades de colonialidad. Correo electrónico: belmontevaleria@yahoo.com.ar
} 


\section{Palabras clave}

Representaciones sociales - diversidad cultural - colonialidad.

\section{Abstract}

The liberal view on the cultural diversity that appears to be pushed from several international agencies such as UNESCO and UNDP, deserves to be revisited. It creates the conditions from which remains unquestioned and voiceless, the logic of power that is involved in the configuration of historically established differences between groups and populations.

To this end, it is appropriate to seek the theoretical contributions, political, ethical and epistemological that, since the mid- ' 90 s of the last century has been conducting a group of intellectuals gathered around the perspective ModernityColoniality- Decoloniality

As methodological strategy for the investigation of the presence of the matrix of colonial power in the modern story on diversity, the article discusses the representations that can be generated around a collective identification of origin as is the modern nation; on this occasion it is representations of the argentine nation.

\section{Keywords}

Representations social - cultural diversity - coloniality.

No se cambia el mundo sin que las personas que hacen el mundo cambien

Walter Mignolo

\section{Parte I}

Los organismos internacionales como la UNESCO y el PNUD vienen elaborando desde finales del siglo pasado y durante la primera década del presente -desde una retórica multiculturalista y pluralista- una serie de documentos $^{1}$ y disposiciones con

\footnotetext{
${ }^{1}$ Entre los más recientes de tales documentos podemos nombrar los siguientes: Nuestra diversidad creativa (1996), la Declaración sobre la diversidad cultural (2001), la Convención sobre la Protección y promoción de la Diversidad de las Expresiones Culturales (2005). En el caso del PNUD encontramos el Informe Mundial sobre Desarrollo Humano (2004) que lleva por título La libertad cultural en el mundo diverso de hoy (Nivón Bolán, 2013). Muchos de estos documentos y otros más pueden consultarse en la página oficial de la UNESCO www.portal.unesco.org. Allí figura un listado de documentos, foros, publicaciones de dicho organismo sobre el tema de la diversidad cultural.
} 
argumentos a favor de la protección y preservación de la diversidad cultural en distintos ámbitos sociales como la salud, la educación y la cultura, entre otros.

Para la mayoría de los gobiernos de Latinoamérica, tales argumentos suelen adquirir el estatuto de 'recomendaciones', razón por la cual dicha temática deviene en una cuestión protagónica en torno a la cual, en las últimas décadas, se han venido diseñando distintas políticas y programas. $^{2}$

El tema de la diversidad ha recibido históricamente distintos abordajes que van desde prácticas xenófobas y racistas hasta la interculturalidad, pasando por la asimilación y el multiculturalismo. Estas últimas recurren en su implementación a estrategias de tipo integracionistas, que buscan el reconocimiento de grupos y expresiones cuya existencia parecería estar siendo amenazada por la tendencia a la homogeneización y a la uniformidad cultural generada por el actual proceso de globalización. En este trabajo se plantea la necesidad de revisar el modo de gestionar la diversidad que ellas promueven, dado que este se asienta sobre una matriz hegemónica, occidental y etnocéntrica, dentro de la cual permanece incuestionada e invisibilizada la lógica de poder que interviene en la configuración de tal diversidad.

Desde este discurso liberal, la diversidad cultural es tratada como si se tratase de un dato inherente a la naturaleza humana; apelando para ello a una retórica de la 'igualdad' desde la cual se diseñan políticas de reconocimiento e inclusión de aquello 'otro' que es concebido como diferente. Desde tal 'epistemología de la igualdad', permanece opacada la huella de todo aquello que se toma como referente, es decir, la asimetría epistémica que distancia y separa a quienes son los encargados de 'incluir' ' y 'reconocer', de aquellos quienes son 'incluidos' y reconocidos, por efecto del propio poder, no es problematizada.

Desde una perspectiva crítica de la sociocultura de nuestro presente, este artículo se propone señalar la permanencia de la lógica de poder que ha intervenido históricamente en la configuración de las diferencias culturales, tanto en la región latinoamericana como en otras partes del mundo donde la colonialidad ha dejado su marca. Al mismo tiempo, busca describir la singularidad que en el presente global asume dicha lógica en relación con el tema de la diversidad.

Para ello, reúne algunos de los principales aportes teóricos, políticos, éticos y epistémicos provenientes de intelectuales agrupados en torno a la perspectiva Modernidad-Colonialidad-Decolonialidad, ${ }^{3}$ en adelante $M C D$, a la cual se le atribuye el

\footnotetext{
${ }^{2}$ Uno de los ámbitos sociales donde la temática de la diversidad ha recibido mayor tratamiento desde esta perspectiva liberal ha sido el de la educación.

3 Una genealogía sobre la conformación de esta perspectiva de pensamientos puede consultarse en Mignolo W. (2007) El pensamiento decolonial. Desprendimiento y apertura. Un manifiesto, en Castro-Gómez, S. y Grosfoguel R. (Eds.) El Giro Decolonial: Reflexiones para una diversidad epistémica más allá del capitalismo global. Pontificia Universidad Javeriana/Siglo del Hombre Editores, Bogotá (págs. 25-26). También en otros trabajo tales como: Borsani M. E (2012) Acerca del giro decolonial y sus contornos, En Observaciones Latinoamericanas. Valparaíso. Ediciones Universitarias de Valparaíso y Fondo Nacional de
} 
mérito de haber impulsado una teoría acerca de la experiencia histórica y cultural latinoamericana desde una perspectiva crítica centrada en torno a la categoría de 'colonialidad del poder'4 propuesta por el sociólogo peruano Aníbal Quijano (Quintero, 2009).

En este trabajo, la estrategia metodológica utilizada para reflexionar sobre la injerencia de la colonialidad en el relato moderno sobre la diversidad, ${ }^{5}$ consiste en analizar la presencia de esta matriz en las representaciones de la nación. Esta propuesta metodológica se fundamenta en al menos dos supuestos teóricos de fondo. Uno de ellos relacionado con la concepción de nación que aquí se sostiene, para la cual esta es ante todo un invento moderno ${ }^{6}$ configurado material y simbólicamente, en torno al cual se establecen criterios de inclusión y exclusión que generan un 'nosotros' al tiempo que construyen un 'otros'. Desde esta concepción, la diversidad se hace presente toda vez que se alude a la nación como colectivo de identificación. El otro supuesto está vinculado al modo como se piensa la relación entre un mundo social, en cuyo seno la colonialidad se encuentra instituida, y el universo simbólico representacional. Se concibe a lo representacional como dimensión co-constitutiva de lo material y a la inversa, lo material como co-constitutivo de lo representacional. Dicho en términos más sencillos, entre ambos campos, el representacional y el material, hay una relación de inherencia recíproca, el mundo social es en y por el conjunto de sentidos, valores, creencias, ideas que en él circulan y al mismo tiempo este universo representacional solo es posible a partir de las condiciones materiales que lo hacen ser. En este trabajo, esta vinculación se toma como la base argumental a partir de la cual se hace posible pensar la relación entre colonialidad y representación o, para decirlo en otros términos, la injerencia de la colonialidad en el espacio simbólicorepresentacional.

A efectos del análisis que se presenta en la segunda parte del trabajo, este se inicia con una caracterización del 'relato moderno sobre la diversidad'. Dicha caracterización procura revelar la permanencia de la estructura de poder que existe en su seno y que da lugar a su continuidad histórica.

Cultura y las Artes y Quintero, P. y Petz, I. (2009) "Refractando la modernidad desde la colonialidad. Sobre la configuración de un locus epistémico desde la geopolítica del conocimiento y la diferencia colonial". En Gazeta de Antropología, Universidad de Granada.

${ }^{4}$ Recordemos que la noción de colonialidad del poder fue creada a mediados de la década de 90 por el sociólogo peruano Aníbal Quijano para caracterizar el patrón de poder del sistema mundo moderno colonial. Es introducido por primera vez en un artículo que Quijano escribió junto a Immanuel Wallerstein titulado: "La americanidad como concepto y el lugar de las américas en el sistema mundo moderno" (Quintero, P., 2009).

${ }^{5}$ Esta temática se desprende de uno de los ejes de análisis del proyecto de investigación en el seno del cual este artículo es elaborado: "El presente en tiempos globales. Geopolítica del conocimiento y nuevas modalidades de colonialidad". Dicho eje se vincula con la pregunta por el presente en tiempos globales y las nuevas modalidades de colonialidad que estarían teniendo lugar en él.

${ }^{6}$ Tal el modo como Eduardo Grüner (2009) alude al estado-nación en el prólogo al libro de Butler, Judith y Chakravorty Spivak, Gayatri (2009) ¿Quién le canta a la nación? Buenos Aires: Paidós. 
Para mostrar la singularidad de esa estructura de poder, se apela a la noción de 'diferencia colonial', propuesta por el semiólogo argentino Walter Mignolo. Con esa expresión el autor alude a un tipo particular de relación social que interviene en la génesis de la producción de las diferencias a partir del periodo colonial. Asimismo, la idea de 'colonialidad del poder' (Quijano), que también es utilizada a lo largo del trabajo, permite comprender cuál ha sido la lógica histórica de funcionamiento de dicha estructura de poder.

Lo anteriormente señalado ubica la propuesta de pensamiento MCD como el marco explicativo a partir del cual se desarrolla la línea argumental del trabajo, principalmente en su primera parte. En la segunda parte, se busca operacionalizar algunas de las categorías ofrecidas por ese marco explicativo. Para ello se recurre al análisis de dos cortos audiovisuales que han sido seleccionados de un total de veinticinco producidos por distintos directores cinematográficos del país a pedido del Ministerio de Cultura de la Nación en el marco de los festejos por el Bicentenario. Los cortos seleccionados se titulan: Argentina del Bicentenario: Las voces y los silencios, dirigido por el cineasta Carlos Sorin y Para todos los hombres y mujeres de buena voluntad, cuyo director es Ricardo Wullicher. ${ }^{7}$

Además de las nociones teóricas ofrecidas por el colectivo MCD, en esta segunda parte se apela a otras, provenientes de distintas tradiciones teóricas críticas, como es el caso de la noción de 'estereotipación', creada por Stuart Hall (1997). En el análisis propuesto, esta noción es utilizada para atender al modo como las representaciones sobre la nación se hallan contenidas dentro de los márgenes de un régimen racializado de representación, lo cual indicaría también en ellas la presencia de la colonialidad.

Por último, cabe señalar que para abordar el vínculo entre la colonialidad como estructura de poder y cierto universo representacional, al que se ha hecho referencia anteriormente, se acude a la teoría sobre las representaciones que el historiador Rocher Chartier desarrolla en su obra El mundo como representación y de la cual se extraen aquí algunas premisas que serán comentadas en los próximos apartados.

\section{I.1 A propósito del relato moderno sobre la diversidad}

La noción de relato, utilizada incluso en el propio título de este trabajo, hace referencia al estatus ficcional que en determinado momento histórico es asumido por un particular modo de concebir el mundo. Se trata de una inventiva establecida desde ciertos espacios de poder que posee efectos simbólicos y materiales muy concretos. En su configuración intervienen sistemas de creencias, valores e imágenes sin ningún tipo de valor referencial, pero que, a través del establecimiento de determinadas

\footnotetext{
${ }^{7}$ Disponible en http://www.25miradas.gob.ar
} 
correlaciones de fuerza, logran imponerse como ideas universalmente válidas y verdaderas.

La modernidad entendida como forma histórica de organización social posee un sistema simbólico mediante el cual se construye el relato que la legitima como tal. En su análisis sobre la especificidad histórica del patrón de poder moderno colonial, Aníbal Quijano (2009) toma nota de esta dimensión simbólica del poder y señala que:

Todo patrón de poder que se va produciendo en el tiempo, y este en particular, va produciendo también su propio sentido, va produciendo su propia manera de entender, de hacer entender, de explicar, de ver, de distorsionar, como todo horizonte de sentido, por eso es parte del patrón de poder (Quijano, 2009). ${ }^{8}$

En relación con lo dicho, la expresión 'relato moderno sobre la diversidad' es utilizada en este artículo para hacer referencia al horizonte de sentidos establecido por la modernidad, mediante el cual las diferencias existentes entre distintos grupos humanos son interpretadas como si fueran diferencias naturales. Este efecto ideológico muestra una singular manera de intervención del poder en la configuración de dicho relato, pues lo hace apelando a una estrategia que oculta mostrando, es decir, se genera cierto efecto simbólico que lleva a las personas a percibir unos fenómenos con la apariencia de otros. La desigualdad asume así la apariencia de igualdad, la continuidad de discontinuidad, por dar solo algunos ejemplos. En este orden de cosas, existen ciertas ideas que son desplegadas por el pensamiento liberal en el imaginario social que al plasmarse en creencias del tipo 'todos somos iguales' o que 'el racismo y la xenofobia son prácticas del pasado' muestran la fuerza ideológica de este relato. Cabe reconocer que un planteo como el que se acaba de hacer merecería un análisis más profundo en términos de teorías del poder y de su dimensión ideológica, análisis que excedería el propósito de este trabajo. ${ }^{9}$ No obstante ello, interesa señalar la invisibilización y el ocultamiento como los principales artilugios con los que opera la matriz de poder, dado que estos se encuentran en la base de la perspectiva de pensamiento MCD que tomamos aquí como marco explicativo para el análisis del relato moderno sobre la diversidad. Por ejemplo, Walter Mignolo, uno de los

\footnotetext{
${ }^{8}$ La cita fue extraída de una conferencia dictada por Aníbal Quijano en el marco del XXVII Congreso de la Asociación Latinoamericana de Sociología, dictada el 4 de Septiembre de 2009.

${ }^{9}$ Sobre este tema se recomienda consultar las obras del filósofo esloveno Slavoj Žižek, así como las del inglés Terry Eagleton. Ambos han indagado profundamente sobre el poder de la ideología en las sociedades modernas.
} 
principales referentes del grupo, afirma, en relación con ello, que "la modernidad es una retórica que oculta la lógica de la colonialidad" (Mignolo, 2012). ${ }^{10}$

Continuando con el tema del 'relato moderno sobre la diversidad', este se gesta con el nacimiento de la modernidad, en el siglo XVI, en el marco de la conquista de América, y se mantiene incesante a lo largo de la historia. En la actualidad, aparece siendo narrado por cierto discurso oficial puesto de manifiesto en una serie de documentos elaborados por organismos internacionales como la UNESCO y el PNUD.

Como ha sido señalado anteriormente, la permanencia histórica de dicho relato deriva de la vigencia que asume el esquema de poder que opera en su seno, el cual alcanza a las distintas modalidades de tratamiento de la diversidad que han existido y existen en la modernidad. Tal es así, que la idea de raza que durante el periodo colonial actuara como elemento organizador de la diferencia, continúa haciéndolo a través de la noción de cultura. Cuando hoy se habla de 'diversidad cultural', cultura es el término utilizado para clasificar a la población mundial de acuerdo a su sistema de signos considerados inherentes a cada grupo o población: lenguaje, vestimenta, religión, costumbres, etc. Del mismo modo que sucediera con la categoría mental de raza como componente fundacional del patrón de poder moderno colonial a partir de la conquista de América, entre fines del siglo XV y principios del XVI, también aquí parece intervenir un mecanismo que naturaliza las diferencias y con ella las desigualdades sociales.

Aníbal Quijano nombra con el apelativo de 'colonialidad' al carácter específico e histórico del patrón de poder que se gesta a partir de la época colonial. El autor describe este patrón de poder como: "un sistema de dominación asentado en un entramado de relaciones intersubjetivas, basadas en la relación social jerárquica de la población mundial sostenida en la configuración y naturalización de la idea de raza" (Quintero, 2010: 7). En este sistema de dominación aparecen dos ideas fundamentales vinculadas al ámbito subjetivo e intersubjetivo, que han sido las que han configurado el complejo cultural de la modernidad hasta nuestros días: la idea de que los no europeos tienen una estructura biológica no solamente diferente a la de los europeos, sino, sobre todo, pertenecientes a un tipo o a un nivel inferior, y la idea de que las diferencias culturales se encuentran asociadas a tales desigualdades biológicas, negando, por lo tanto, que sean producto de la historia social (Quintero, 2010). Este complejo de ideas impregna todos y cada uno de los ámbitos de la existencia social tomando el nombre de racismo. La raza es para Quijano (2009) un constructo mental generado en el momento mismo en que comienza la violencia de la conquista y que produce la racialización de las relaciones intersubjetivas al jerarquizarlas. Se trata por tanto "de un

\footnotetext{
${ }^{10}$ Estas palabras fueron vertidas por Walter Mignolo en una conferencia que brindó en el año 2012 en el marco del III Encuentro CEAPEDI-Comahue y Encuentro Internacional del Colectivo Modernidad/Colonialidad, los días 9, 10, 11 y 12 de octubre en la ciudad argentina de Neuquén.
} 
producto de la subjetividad que es convertida muy rápidamente bajo la violencia de la conquista en una forma de relación social" (Quijano, 2009: 4). ${ }^{11}$

Un elemento que indicaría la manera como ese complejo cultural de imágenes, actitudes, ideas y prácticas sociales conocido con el nombre de 'racismo' interviene en el discurso oficial de la diversidad se halla en la concepción esencializada de cultura a la que este recurre. Desde dicha concepción, la diferencia cultural queda despojada de todo condicionamiento histórico y social y es asumida tan solo como una cuestión natural. En nuestro presente global, esta naturalización de la diferencia es promovida por una lógica multicultural y pluralista que inventa un tipo de relación sociocultural entre las culturas y los grupos basada en criterios de equidad, igualdad y simetría. Esta modalidad hegemónica de establecer diferencias entre culturas - de clasificar- expresa la eficacia simbólica y material de una estructura colonial de poder que ha dispuesto históricamente en posición desigual a poblaciones y grupos. ${ }^{12}$

Distintos organismos internacionales ocupan un rol destacado en la comunicación de esta visión liberal sobre la diversidad. Tal es el caso de la anteriormente nombrada UNESCO, que según manifiesta el teórico argentino Eduardo Domenech "se ha convertido en uno de los organismos que con mayor fuerza promociona a través de sus programas, declaraciones y recomendaciones, una visión armónica horizontal y de enriquecimiento mutuo de las relaciones étnicas y culturales" (2005: 11).

Esta visón despolitizada sobre la diversidad ha sido ampliamente discutida por distintos referentes de la teoría crítica de la cultura. El antropólogo argentino Alejandro Grimson señala al respecto que: "la diversidad no debe comprenderse como un mapa esencializado y trascendente de diferencias, sino como un proceso abierto y dinámico, un proceso relacional vinculado a las desigualdades y a las relaciones de poder" (Gromson, 2011: 78).

También Rita Segato (2007) en la introducción a su libro La nación y sus otros señala la imprudencia de vaciar a las identidades, aun a las identidades culturales, del juego histórico que las produjo.

En este mismo sentido se expresa la filósofa Elizabeth Jelin cuando indica que "la percepción y la categorización de las diferencia ha sido la base de la dominación" (Jelin E. y otros, s/f).

\footnotetext{
${ }^{11}$ Ideas expresadas por Aníbal Quijano en una conferencia dictada en el marco del XXVII Congreso de la Asociación Latinoamericana de Sociología, el 4 se Septiembre de 2009.

${ }^{12}$ Para comprender el planteo expuesto, conviene recordar la particular concepción de Quijano sobre el poder. Este autor define el poder como un espacio y una malla de relaciones sociales de explotación, dominación y conflicto articuladas, básicamente, en función y en torno de la disputa por el control de los distintos ámbitos de existencia social. Uno de esos ámbitos es el de la subjetividad y sus productos, materiales e intersubjetivos, incluido el conocimiento. Una clara manifestación del poder en este ámbito de existencia social queda en evidencia cuando el autor afirma que "la idea de raza no es solamente que sirvió para hacer que los unos dominaran a los otros, sino que enseñaron a sus víctimas a mirarse con los ojos del dominador" (Quijano, 2009: 9).
} 
A partir de estas afirmaciones que invitan a un análisis crítico del relato moderno sobre la diversidad, el presente trabajo insiste en indagar la injerencia de la colonialidad en él.

\section{I.II. La diferencia colonial en la constitución del relato moderno}

La tarea de re-politizar la cuestión de la diversidad requiere la revisión de nociones que aparecen en la superficie del relato moderno; una de ellas es la noción de 'diferencia cultural'. Su examen posibilitaría poner de manifiesto la especificidad o singularidad de las diferencias que se establecen en dichas relaciones y que asumen la apariencia de 'diferencias culturales'. En otras palabras, se intenta decir que la diferencia cultural supone ante todo una diferencia de poder. $\mathrm{O}$, más específicamente y para usar una noción diseñada desde la perspectiva decolonial, la diferencia cultural supone 'diferencia colonial'.

Con el término 'diferencia colonial' el semiólogo argentino hace referencia a "la clasificación del planeta en el imaginario moderno/colonial, por la promulgación de la colonialidad del poder, una energía y maquinaria que transforma diferencias en valores" (Walsh, 2007: 21). La 'diferencia colonial' soporta una lógica que clasifica a las personas en el planeta por sus lenguas, sus religiones, sus naciones, su color de piel, su grado de inteligencia, etc. (Mignolo, 2003). En tal sentido, esa lógica de clasificación supone una distribución diferencial de poder en la configuración de las relaciones intersubjetivas, puesto que "al clasificar e identificar a los grupos y poblaciones en sus faltas o excesos se marca la diferencia y la inferioridad con respecto a quien clasifica" (Mignolo, 2003: 39). Ese diferencial de poder es precisamente el que, siguiendo el análisis que aquí se propone, parecería quedar soslayado en la utilización modernoliberal de la noción de 'diferencia cultural'.

La 'diferencia colonial', así como el control y producción de subjetividades que ella conlleva, se gesta durante el periodo colonial en torno a la relación colonizador/colonizado y se mantiene vigente a lo largo de la historia gracias a un dispositivo o fuerza motriz (Mignolo) llamada 'colonialidad del poder'. En este sentido, se dice que la colonialidad del poder ha sido la lógica histórica de la diferencia colonial. Esta colonialidad no es otra cosa que la malla o espacio, según los términos utilizados por Quijano, en el que se establecen las relaciones sociales. Ese tejido abarca diferentes ámbitos de la existencia social, dentro de los cuales se encuentra uno que aquí interesa especialmente: el de la subjetividad y los vínculos intersubjetivos. ${ }^{13}$ Interesa porque es este ámbito el que permite dar cuenta del modo como toda la dimensión del ser, es

\footnotetext{
${ }^{13}$ Este es uno de los cinco ámbitos de existencia social del poder que señala Quijano, los otros cuatro tienen que ver con el trabajo, la naturaleza, el sexo y la autoridad.
} 
decir desde lo que se piensa, percibe, hasta lo que se actúa, estaría siendo atravesada por la colonialidad.

Respecto a este último planteo, el sociólogo puertorriqueño Ramón Grosfoguel al referirse a la colonialidad como "ese trazo ausente que nos constituye en su perenne invisibilidad" (2009: 11), señala el nivel de imperceptibilidad que para la conciencia humana tiene la intervención de la colonialidad. En esta misma línea argumental, otro referente del grupo, Nelson Maldonado-Torre, afirma que "respiramos colonialidad en la modernidad cotidianamente" (2007: 31). De esta manera, ambos autores hacen alusión al lugar hegemónico que -desde la constitución de América- ${ }^{14}$ asume la colonialidad como horizonte de sentidos.

Con lo expresado hasta aquí puede decirse que la colonialidad es una matriz constitutiva de la subjetividad, puesto que opera en todo los ámbitos del ser, incluyendo las dimensiones cognitivas, imaginarias y representacionales. Precisamente en relación con esto último, en el próximo apartado se alude a la manera en que la colonialidad interviene en los modos de representación social.

\section{I.III. Sobre la colonialidad en las (re)presentaciones de la nación}

La cuestión de las representaciones sociales se aborda aquí desde el planteo teórico que sobre el tema ha venido realizando el historiador Roger Chartier (1992). En pocas palabras, dicho planteo establece una relación co-constitutiva entre un mundo material y otro que podríamos llamar simbólico. Las ideas, imágenes, creencias, símbolos y representaciones no son concebidos como meras manifestaciones simbólicas de cierta dimensión material expresada en una base económica, en un sentido marxiano. Por el contrario, es precisamente en ellas, en tanto ámbitos concebidos como mediaciones simbólicas, donde también se configura el poder. En este sentido afirma Chartier que "No hay práctica ni estructura que no sea producida por las representaciones, contradictorias y enfrentadas, por las cuales los individuos y los grupos dan sentido al mundo que les es propio" (1992: IV). Para este autor toda creación -y las prácticas representacionales suponen algo del orden de lo creativo-, inscribe en sus formas y sus temas una relación con las estructuras fundamentales que en un momento y en un lugar dado organizan y singularizan la distribución del poder y la organización de la sociedad. En esta misma línea, expresa que en todo proceso creativo existe cierto condicionamiento social a través de coacciones de distinta especie. A una de esas especies de coacciones la llama 'coacción fundamental'. Con ella hace referencia a las determinaciones ignoradas que hacen que ciertas imágenes sean concebibles, comunicables y comprensibles.

\footnotetext{
${ }^{14}$ Para Quijano, América Latina fue el espacio original y el tiempo inaugural de un nuevo patrón de poder, históricamente específico, cuya colonialidad es su característica, su inextricable rasgo fundacional e inherente desde hace poco más de quinientos años hasta hoy (Quijano, 2009).
} 
De acuerdo con los argumentos que se vienen desarrollando sobre el lugar de la colonialidad en la configuración del orden cultural de la modernidad, es posible pensar que ella, la colonialidad, se halla en la base de la existencia social y se expresa en ese complejo ideológico cultural de imágenes, actitudes, ideas y prácticas sociales que conocemos como racismo. Así, pues, se explica su protagonismo en la configuración de prácticas representacionales. Para utilizar los términos propuestos por Chartier, podría decirse entonces que, como 'coacción fundamental', la colonialidad interviene en los modos de representación del mundo.

Sobre este desempeño de la colonialidad en el plano de la subjetividad se ha expresado Aníbal Quijano, para quien ciertas ideas fundamentales que se encuentran vinculadas al control y producción de la subjetividad han configurado el complejo cultural de la modernidad hasta nuestros días. Ellas, según el autor, operan a partir de una clasificación jerárquica de los grupos y poblaciones por diferencias atribuidas a criterios biológicos naturales, expresada en la idea según la cual ciertos grupos son naturalmente inferiores a otros. Dichas ideas pueden ser leídas como manifestaciones de poder, dado que no solo suponen una acción diferenciadora y desigualadora de la diferencia, sino que, como hemos señalado anteriormente, poseen un fuerte componente naturalizador.

Lo dicho hasta el momento permite concluir que habitamos, según los términos utilizados por Stuart Hall (1997), un régimen 'racializado de representación', en el cual existen prácticas de representación más comunes que otras, una de ellas es la 'estereotipación'. Con dicha noción, Hall alude a la práctica típica de representación dentro de un régimen racializado. Se trata de una práctica que opera a través de una estrategia representacional diseñada para fijar la 'diferencia' y así asegurarla para siempre bajo el nombre de 'naturalización'. La naturalización se lleva adelante a través del estereotipo. El estereotipo reduce a las gentes a unas cuantas características simples (Hall), en este sentido tiene efectos esencializantes, reduccionistas y naturalizantes.

Precisamente, el análisis que se propone a continuación recurre a esta noción para dar cuenta de la presencia de la colonialidad en las representaciones de la nación.

\section{PARTE}

En esta parte del trabajo se analiza el par de cortometrajes mencionados al inicio, buscando comprender el modo como se manifiestan empíricamente algunas de las principales categorías analíticas expuestas en la primera parte.

Las conclusiones a las que se arriba no buscan ser exhaustivas, simplemente, tratan de poner de relieve el espacio de la subjetividad/intersubjetividad, en tanto ámbito de existencia social, como lugar donde también se configura el poder.

A continuación se presenta un análisis reflexivo de cada uno de los cortos seleccionados: Argentina del Bicentenario: las voces y los silencios y Para todos los 
hombres y mujeres de buena voluntad, precedidos, ambos, por una breve presentación descriptiva como modo de facilitar su comprensión al lector.

\section{Cortometraje $\mathbf{N}^{\circ} 1$ Argentina del Bicentenario: las voces y los silencios}

El relato fílmico está conformado por dos grandes secuencias escénicas, una que lleva por título 'Las voces' donde el lenguaje verbal prevalece como modalidad enunciativa y otra, titulada 'Los silencios', donde predomina el lenguaje icónico.

La primera de estas secuencias inicia con una escena donde se muestra la figura del historiador argentino Mario O'Donnell sentado en un sillón de frente a la cámara. El historiador se encuentra hablando sobre la historia argentina contemporánea. En su alocución refiere especialmente al periodo conocido como 'Proceso de Organización Nacional' que fuera iniciado una vez finalizado el enfrentamiento entre Buenos Aires y la Confederación, y cuyo desenlace generara el triunfo de la oligarquía librecambista portuaria en la batalla de Pavón. A lo largo de su disertación, O’DonnelI se centra en remarcar el carácter significativo que asume la dicotómica imagen sarmientina de 'civilización o barbarie' en la cultura nacional. Seguidamente, se muestra otra escena constituida también por la imagen de un intelectual, se trata del historiador Carlos Altamirano. En la escena aparece Altamirano sentado en un sillón en similar posición a la que minutos antes se encontraba O' Donnell. Las palabras de Altamirano, casi en el mismo sentido que las de su predecesor, remarcan el carácter confrontativo que en los últimos cien años asumiera la historia política argentina a partir de la contraposición entre democracia y república. Cada una de las escenas se encuentra acompañadas de un epígrafe que indica el tema de la exposición: Civilización o barbarie, cuando habla O' Donnell y Democracia o república, cuando lo hace Altamirano.

La segunda gran secuencia lleva por título "Los silencios", en alusión a una de las partes que componen el título general del corto. Corresponde a una serie de tomas fílmicas que transcurren de manera lenta y sucesivamente, en las que se muestran imágenes de niños y niñas en escenarios naturales de distintas provincias del noroeste argentino. Dichos escenarios naturales están constituidos por diversas situaciones que parecerían formar parte de las vidas cotidianas de esos niños y niñas, el juego y la recreación en el patio escolar, el trabajo en los campos de algodón y en los hornos de carbón. También las escenas muestras distintas prácticas y costumbres con las que suele caracterizarse a los habitantes del norte del país. Otras imágenes muestran espacios de los que participan los niños y las niñas, desde un comedor hasta un santuario. En la mayoría de los casos las imágenes de los niños y las niñas aparecen en un primer plano del cuadro. Mediante este recurso visual parecería quererse apartarlos por un instante del escenario en el que se encuentran. En todos los casos, los niños 
permanecen quietos con sus miradas dirigidas fijamente a la cámara. Un sonido tenue pero fornido acompaña la secuencia. Mientras en esta secuencia el lenguaje icónico prevalece como modalidad enunciativa, como se señaló al inicio, el escrito queda reducido a los epígrafes que aparecen en el inferior del cuadro, indicando, en todos los casos, el nombre del niño o la niña, su edad y el sitio o ubicación geográfica donde trascurre la escena. Las imágenes fijas duran unos escasos segundos y van sucediéndose de manera lenta.

\section{Análisis}

Uno de los elementos a resaltar tiene que ver con cierta discordancia que se observa en la operatoria constructiva general del relato fílmico. Mientras en el plano de la oralidad, a través de las palabras de los intelectuales, se impugna el diseño dicotómico que la nación argentina asumiera a partir de las ideas políticas de la generación del 37, en la configuración material del relato se utiliza como recurso constructivo general un esquema que no escapa a esa dicotomía. Es decir, la imagen dicotómica de 'civilización y barbarie' es finalmente la que domina el criterio a partir del cual se construye todo el relato fílmico. De un lado, 'las voces', representadas por la figura del intelectual símbolo de la razón moderna. Por otro lado, 'los silencios', representados por rostros impávidos pertenecientes a niños y mujeres, en su mayoría aborígenes, que habitan distintas provincias del noroeste argentino, quienes, dentro de un régimen colonial de representación, simbolizan la tradición, la ignorancia, el atraso y lo local.

Dicha discordancia parecería estar indicándonos cuán eficazmente continúa funcionando la matriz de poder colonial constitutiva del proyecto político, epistémico y civilizatorio de occidente al impedir la emergencia de un conocimiento del mundo de otro modo. En otros términos, es la mítica contraposición entre la ciudad cosmopolita occidental y el supuesto atraso cultural, económico y político del vasto territorio nacional (Grimson, 2012: 121) que como figura colonial parecería, en este caso, haberse apoderado del relato fílmico.

Recordemos que Mignolo alude a la construcción colonial de la diferencia en pos de afirmar que esta no puede ser rotulada como cultural sin más, sino que esta diferencia responde a la ocupación de lugares de poder que la experiencia colonial ha determinado. Como señalamos en la primera parte del trabajo, ha sido la colonialidad, como patrón de poder específico de la modernidad, la que ha mantenido intactos estos lugares de poder. En este sentido, se puede pesar que el artilugio discursivo de distinguir, separar, confrontar a 'las voces', por un lado y a 'los silencios', por el otro, estaría poniendo de relieve la colonialidad del poder. Entre 'las voces' y 'los silencios' tal como aparecen concebidas en el relato fílmico- lo que está en juego no es otra cosa que un canon diferencial de poder.

Otro de los elementos discursivos que también parece responder a la arbitrariedad de una epistemología etnocéntrica es el régimen de mirada que opera a lo largo del 
relato. Las imágenes se muestran ocultando toda sospecha respecto a quién es y desde qué lugar se ubica quien mira. No solo se oculta todo referente ocular, sino también la posición jerárquica que este asume en el acto de mirar, generando así una 'falsa simetría'. En esta falsa simetría se asienta un régimen de la mirada en el que opera la 'colonialidad del ver'. En dicho régimen aparece incuestionado quién es el que mira y desde qué lugar mira. La cámara no es sino la ciudad que mira al interior, la elite que mira al pueblo, el opresor que mira al oprimido. La mirada fija a cámara como modalidad que se le es aparentemente 'exigida' a cada uno de los niños y las niñas que aparecen en el corto, estaría poniendo en evidencia la disposición histórica que los atraviesa y los constituye como objetos dispuestos para ser mirados. De manera muy similar a como en los museos se montan las piezas históricas, aquí las escenas van sucediéndose al tiempo que cambian sus nomencladores.

Pero la colonialidad opera también a través de otros elementos que aparecen en el discurso cinematográfico en tanto modalidad representacional, por ejemplo, en la construcción simbólica de la diferencia, acudiendo a la estrategia que ha sido denominada en la primera parte del trabajo como 'práctica de estereotipación'. Como se ha dicho, el estereotipo reduce 'lo otro' a unos pocos rasgos esenciales y fijos en la naturaleza. En este sentido, en el relato analizado, el noroeste argentino aparece representado mediante el estereotipo de lo inmenso, impasible, silencioso y homogéneo. Otro de los signos que ponen de manifiesto la estrategia discursiva de naturalización de la diferencia tiene que ver con la práctica de homogeneizar étnica y culturalmente, ella recurre a la mostración de rostros que guardan entre sí una gran similitud en cuanto a rasgos fenotípicos tales como el color de la tez, del cabello, la estatura, entre otros.

Los anteriores son algunos de los signos que ponen de manifiesto la presencia de la colonialidad en las prácticas representacionales.

\section{Cortometraje $\mathbf{N}^{\circ} 2$ Para todos los hombres y mujeres de buena voluntad}

Como estrategia constructiva se recurre a la combinación de imágenes que responden a distintos formatos visuales. Estas imágenes, al ser reunidos en un mismo relato fílmico, aparecen como partes integrantes de un único discurso.

Una gran situación actúa como contexto escénico dentro del cual, de manera intercalada, se despliega el resto de las escenas. Se trata de una orquesta instrumental que, siguiendo las indicaciones de un director de orquesta, ejecuta un amplio repertorio del cancionero nacional argentino (el Himno Nacional Argentino, la canción a Mi bandera y Aurora). Este comienza y finaliza con las estrofas de nuestro himno nacional. Las distintas canciones se suceden en un montaje continuo a lo largo del cual diferentes voces van apropiándose de la entonación de las estrofas sonoras. Un rasgo significativo en este relato es el modo como la uniformidad que imprime el ritmo 
sonoro, resulta quebrantada por las diversas entonaciones y acentos que con gesto efusivo añaden quienes cantan.

El canto se inicia con las voces de las comunidades étnicas de argentina que se expresan en lenguas nativas tales como el quechua, guaraní y aimara. Luego continúa con las voces de los representantes de las distintas colonias y colectividades inmigratorias entre las que pueden verse a galeses, armenios, suizos, vascos, españoles, turcos, italianos, israelíes, franceses, portugueses y afrodescendientes. En todos los casos se monta una escena donde los rostros de quienes cantan aparecen ocupando un primer plano del cuadro junto a una gran exhibición de coloridas vestimentas y distintas simbologías características de cada una de las respectivas culturas. Al mismo tiempo, entre las imágenes de los rostros cantando y de la orquesta ejecutando, se intercala un montaje de imágenes que muestran distintos sucesos de la historia política, económica y social de la Argentina moderna. Las imágenes del montaje refieren en particular a escenas que muestran el protagonismo asumido por el pueblo argentino en distintos episodios históricos y políticos. Se muestran acontecimientos que van desde la llamada 'Campaña del desierto' hasta el periodo en el que se restablece el orden institucional democrático, en 1983. La música es utilizada de manera significativa a lo largo de todo el relato, por ejemplo, su ejecución se detiene cada vez que las imágenes muestran episodios violentos que en cierto momento histórico han irrumpido en la vida y el orden democráticos de la nación argentina.

\section{Análisis}

La metáfora del 'crisol de razas' aparece como referencia central del relato fílmico. Esta figura retórica, devenida en mito fundacional, ha servido históricamente como base del imaginario de la nación y del control de la diferencia etno-racial y colonial dentro de ella (Walsh, 2006).

La relación directa entre mestizaje y ciudadanía es invocada a través de la referencia al colectivo universal que supone la expresión 'todos' que aparece desde el título del corto, Para 'todos' los hombres y mujeres de buena voluntad.

A este particular modo de percibir a la nación sirven distintos dispositivos de producción simbólica que estimulan un cierto sentimiento de mancomunidad. Entre ellos se encuentran los mitos unificadores, las literaturas canónicas, el relato histórico oficial, entre otros.

También la música aparece como recurso simbólico. A ella se apela como espacio en el que se condensan y unifican las diferencias. Sin embargo, también asume otra significación a lo largo del relato. El énfasis que en él se le es otorgado a los distintos modos de entonación para dar cuenta de la variedad de acentos regionales parece ocultar el hecho de que lo que se canta no es sino un único y mismo repertorio. De esta manera la 'diversidad cultural' queda subsumida en la homogeneidad de la monocultura nacional que se presume a partir del repertorio elegido. A los distintos 
grupos étnico-culturales que son así 'incluidos', se les concede, en tanto 'otredad', un espacio en la insularidad del orden nacional, pero dejando incuestionada la base ideológica de la nación (Mignolo, 2006). En este sentido, cabe recordar la idea expresada por la filósofa Judith Butler en su obra Quién le canta a la nación, según la cual para producir la nación, que sirve de fundamento para el estado-nación, ella "debe purificarse de su heterogeneidad, excepto en los casos donde cierto pluralismo permita la reproducción de la homogeneidad sobre otra base" (2009: 66). En el corto que se analiza aquí, la diversa y heterogénea fisonomía que puebla la nación resulta 'igualada' por la voluntad de un Estado que, como director de una orquesta, concibe a todos sus músicos con el mismo derecho a ejecutar sus instrumentos. De este modo, toda diferencia resulta pues, subsumida por la universalidad política del estado-nación (Chatterjee, 2008).

Sin embargo, retomando al pensador político Partha Chatterjee, esta horizontalidad política, cultural y social que el relato fílmico invoca apelando a cierta idea de 'ciudadanía multicultural', oculta el tratamiento diferenciado que reciben a diario distintos grupos y poblaciones, particularmente en países poscoloniales como el nuestro. De esta manera, el discurso multicultural al que parece estar dándose lugar en el corto, se presenta como el recurso ideológico a partir del cual la diferencia cultural es evocada en el mismo acto en que se oculta la sub-alternización que la constituye como tal.

\section{A modo de cierre}

Este trabajo se trató de una reflexión analítica sobre la fisonomía que asume el poder en la sociedad capitalista actual. En este caso se buscó desmontar críticamente el relato moderno sobre la diversidad a través de indagar la permanencia de la lógica de poder colonial en el tratamiento de la diferencia cultural.

Para dicha indagación se recurrió a algunas nociones teóricas que integran el andamiaje conceptual de la perspectiva Modernidad-Colonialidad-Decolonialidad, las cuales fueron presentadas en la primera parte del trabajo. En la segunda parte se recurrió al estudio de los modos de representación de la diversidad, en este caso mediante el análisis de dos cortometrajes producidos en conmemoración del bicentenario de la nación argentina. En el análisis se expuso la eficacia del poder colonial en la configuración de dichas representaciones a partir de indicar cómo ciertos mecanismo discursivos -naturalización, estereotipación- operan en la narración de la otredad, la diversidad cultural y la identidad nacional. Estos mecanismos, devenidos en 'signos coloniales', vienen a confirmar la máxima sobre la que se asienta toda la perspectiva epistémica, política y ética del grupo Modernidad-ColonialidadDecolonialidad, a saber: que la colonialidad como cara oculta de la modernidad inaugura un sistema de dominación social sin precedentes que persiste más allá de la ruptura del colonialismo como estructura de dominación política específica. 
Del análisis propuesto se desprende como idea central que el discurso liberal sobre la diversidad cultural -puesto en circulación por organismos de gobierno internacionales como la UNESCO, el PNUD, entre otros- resulta funcional al orden colonial, dado que en él continúa operando ese complejo cultural de imágenes, actitudes, ideas y prácticas sociales que se conoce bajo el nombre de 'racismo'. Además, que ello sucede toda vez que las distintas culturas son reconocidas atribuyéndoseles determinadas características como si fueran datos de la naturaleza.

Este modo de gestión de la diversidad -en el que opera una lógica multicultural y pluralista- toma la apariencia de igualdad, simetría y democracia cultural cuando en verdad no se hace otra cosa que ubicar a unas culturas en un escalón superior a otras, lo cual explica la vigencia de la diferencia colonial como elemento constitutivo de la diversidad cultural. En relación con esto último, interesa decir que muchas de las luchas sociales de nuestra época, especialmente las llevadas adelante por distintos grupos sociales -mujeres, afrodescendientes, campesinos, comunidades indígenas, como, asimismo, las sexualidades disidentes de la heteronormatividad occidental- apuestan con sus acciones a la transformación de ese diferencial de poder que soporta la diferencia colonial, lo hacen como modo de arribar a una real democratización cultural de nuestras sociedades. En ellas, la interculturalidad se presenta como principio ideológico, político, ético y epistémico de trasformación social.

Por último, cabe señalar que el análisis realizado no solo procuró hacer ver las pretensiones coloniales e imperiales de cierto modo particular de percibir e imaginar las diferencias culturales, sino también manifestar que por más nobles que pudieren ser los intereses que orientan una práctica creativa -como la llevada adelante, en este caso, por realizadores cinematográficos- esta se encuentra siempre condicionada, de alguna manera, por el poder.

\section{Bibliografía}

BORSANI, M.E. (2012). Acerca del giro decolonial y sus contornos. En Caba M. Sergio y García G., Gonzalo (Comps.), Observaciones Latinoamericanas. Valparaíso: Ediciones Universitarias de Valparaíso y Fondo Nacional de Cultura y las Artes.

BUTLER, J. y GAYATRI CHAKRAVORTY S. (2009). ¿Quién le canta al Estado-nación?: Lenguaje, política, pertenencia. Buenos Aires: Paidós.

CHARTIER, R. (1992). El mundo como representación. Historia cultural entre práctica y representación. Barcelona: Gedisa.

CHATTERJEE, P. (2008). La nación en tiempos heterogéneos. Buenos Aires: Siglo XXI.

DOMENECH, E. (2005). (Comp.). Migraciones contemporáneas y diversidad cultural en la Argentina, Centro de Estudios Avanzados, Universidad Nacional de Córdoba.

GRIMSON A. (2011). Los límites de la cultura. Críticas de las teorías de la identidad. Buenos Aires: Siglo XXI editores. 
HALL, S. (2010). El espectáculo del 'Otro'. En Stuart Hall Sin garantías. Trayectorias y problemáticas en estudios culturales. Instituto Pensar, Universidad Andina Simón Bolívar: Envión Editores.

MALDONADO-TORRES, N. (2007). Sobre la colonialidad el ser: contribuciones al desarrollo de un concepto, en Castro-Gómez, S. y Grosfoguel, R. (Eds.). El giro decolonial. Reflexiones para una diversidad epistémica más allá del capitalismo global. Bogotá: Siglo del Hombre Editores.

MIGNOLO, W. (2003). Historias locales/diseños globales. Madrid: Akal.

QUIJANO, A. (2009). "Colonialidad del Poder y Des/colonialidad del Poder", conferencia dictada en el XXVII Congreso de la Asociación Latinoamericana de Sociología, Buenos Aires.

QUIJANO, A. (2011). Colonialidad del poder, eurocentrismo y América Latina en Lander (Comp.) La colonialidad del saber: eurocentrismo y ciencias sociales. Buenos Aires: CLACSO.

QUINTERO, P. (2010). Notas sobre la teoría de la colonialidad del poder del poder y la estructuración de la sociedad en América Latina, en Papeles de trabajo, Vol. 19, 115. Rosario: Centro de Estudios Interdisciplinarios en Etnolingüística y Antropología Socio-Cultural.

QUINTERO, P. y PETZ, I. (2009). Refractando la modernidad desde la colonialidad. Sobre la configuración de un locus epistémico desde la geopolítica del conocimiento y la diferencia colonial. En Gazeta de Antropología, Vol. 25 (2) 1-21: Granada.

SEGATO, R. (2007). La nación y sus otros. Raza, etnicidad y diversidad religiosa en tiempos de Políticas de la Identidad. Buenos Aires: Prometeo. 